\title{
The influence of mascot's modeling characteristics on emotional image
}

\author{
Zhu Zhe ${ }^{1}$, Shi Huimin ${ }^{2}$ * \\ ${ }^{1}$ Visual communication system, Jiangsu University, Zhenjiang, Jiangsu Province, 212000, China \\ ${ }^{2}$ Visual communication system, Jiangsu University, Zhenjiang, Jiangsu Province, 212000, China
}

\begin{abstract}
We intends to investigate the impact of the characteristics of mascots modelling on the emotional imagery based on the theory of perceptual engineering. Specifically, we used the method of semantic difference image cognitive analysis on representative samples by virtue of SPSS software, which completes principal component analysis and regression analysis, typical vocabulary screening, as well as extraction of projects and category of the project modelling using morphological analysis in combination with the theory of science I analysis the correlation coefficient. Eventually, we will translate user's perceptual demand description into rational modelling characteristics, so as to acquire a better understanding of the correlation between mascots modelling characteristic and emotional image, all of which provide certain reference basis for designers.
\end{abstract}

\section{Introduction}

Considered as an important bearing way of design in modern society, mascots have been paid more and more attention by people. Excellent mascot design is recorded in people's mind for a long time with its distinctive shape and vivid image, and it has become the brand and corporate image symbol to be remembered. Study of the mascot in the design market are stays at the level of the design on the surface, with the number of mascots set to feature emotional study remaining relatively small. Moreover, the current research is targeted to theoretical narration with strong subjectivity, and some researchers design experiments to explore the emotions expressed by mascots, but their analysis stays at the level of qualitative analysis, lacking in quantitative analysis shown by experimental data and emotional tendency, the inner link of which deserves further exploration. Based on Kansei engineering, this paper constructs a correlation model between perceptual images and modeling elements to provide theoretical support for mascot modeling design, thus effectively guiding the innovative design of mascots, and thereby win better brand communication effect.

This paper takes the mascot design as the research object and quantifies the type I theory as the principle to study the correlation between the perceptual image of the mascot and its modeling elements, so as to endow the product with a special style and form, which eventually satisfy the psychological needs of contemporary consumers.

\section{Kansei engineering}

Perceptual (Kansei) originated from Japanese the word " カ ン セ 1 " transliteration, it refers to the psychological feelings of consumers and product image cognition. Combined with the engineering technology, perceptual technology is a kind of people-oriented engineering technology, it adopt the method of engineering human feelings and quantify people's emotional information so as to find out the relationship between the perceptual and the engineering quantity, and it translate the perceptual information into the design of the specific form, in order to develop and design products subject in line with the consumer demand.

In daily life, when people observe objective things around them, most of them will have certain psychological activities, and the feelings brought by such activities directly affect the satisfaction of people's inner needs when they understand things. The modeling features of the mascot design are the carrier of the audience's emotional cognition of the mascot. Through the analysis, observation, understanding of the design needs and the application of this in the designing, the designer creates the products that meet people's needs and expectations, and gives people a sense of beauty. Therefore, the basic appeal of design is emotion, only the psychological needs of consumers and use of the feeling of factors combined in the design of each step and link, can designers really effectively solve the design problem. It is the research paradigm of Kansei engineering that all kinds of emotions and feelings brought by products through semantics can be expressed.

Corresponding author's e-mail: 337460060@qq.com 


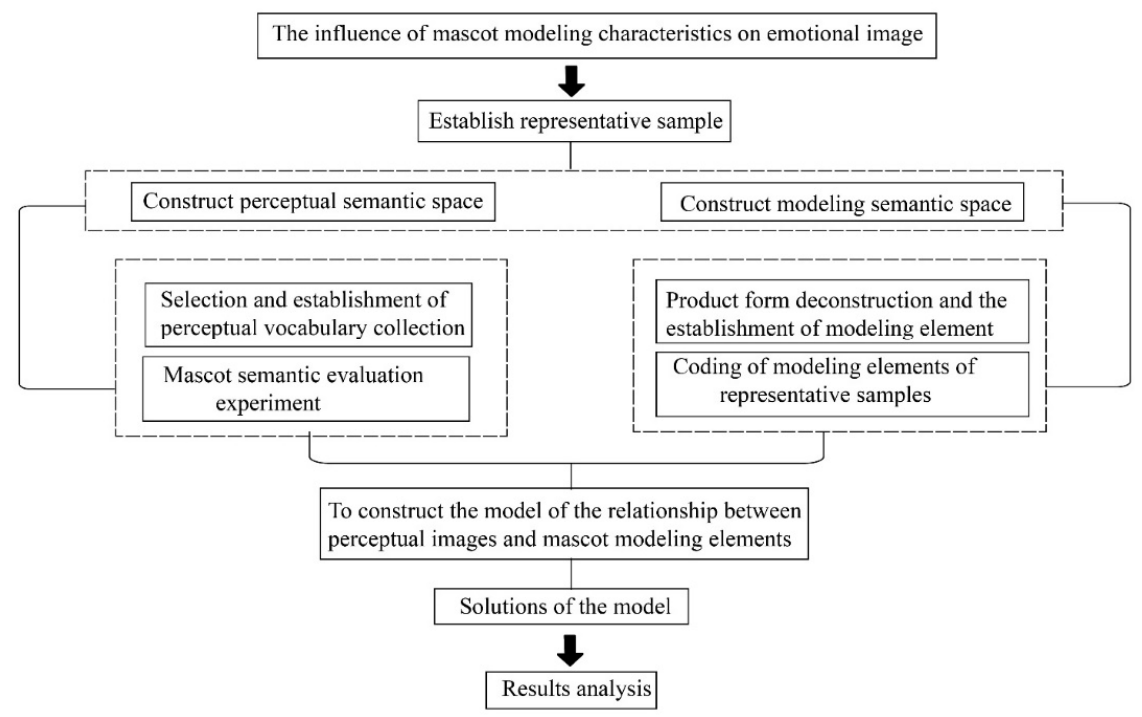

Figure 1. Research flow chart

\section{Research procedures}

\subsection{Establish representative samples}

Mascot categories are numerous and complex, usually with animals or plants as the form of divergence. In order to get a better quantitative analysis, we choose an animal prototype for research. As a common mascot prototype, panda is unique and symbolic enough to convey brand awareness. After many investigations, the mascot with panda as the prototype is selected for emotional research.

A total of 46 images were collected by designing websites, periodicals, magazines, etc, and 21 mascot samples were selected after excluding samples that are too homogeneous or fuzzy. Under the condition of studying the modeling features, the interference factors such as color and volume are excluded, the image is processed in grayscale, and the brightness is adjusted to better maintain the visual consistency of the samples, and the general shape is classified and discharged, so as to facilitate the later modeling extraction [1], as shown in figure 2.

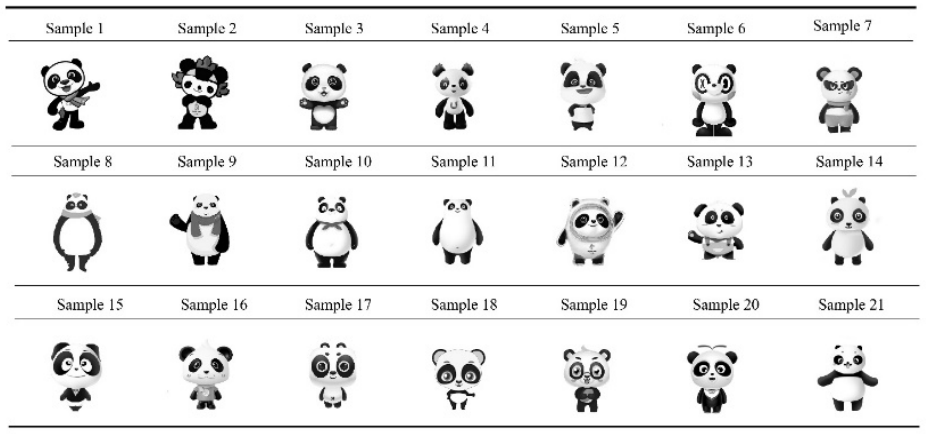

Figure 2. Visual communication system

\section{2. construct perceptual semantic space}

Through brainstorming and network, magazine and dictionaries, dictionaries and so on, we widely collected 40 adjectives for the study, and we kept 10 groups of them, after preliminary screening. Using the Likert scale method, we write the words of opposite meaning on the two ends of the scale, which shows 7 grades of intensity for evaluation, and the middle value is set up as 0 , the left and right extreme values are respectively 3 and -3 . At the same time, samples numbers will be labeled in front of the table ${ }^{[2]}$. Designers engaged in design-related industries were invited to evaluate and score the samples. The subjects expressed their feelings in a quantitative form on the attitude scale of this particular descriptive word, as shown in Table 1. The mean value of perceptual images was obtained by statistical score calculation, as shown in Table. 2 .

Table 1. Perceptual vocabulary scale

\begin{tabular}{ccccccccc}
\hline Image vocabulary & \multicolumn{1}{c}{ score } & \multicolumn{3}{c}{ Image vocabulary } \\
\hline traditional & -3 & -2 & -1 & 0 & 1 & 2 & 3 & modern \\
Personality & -3 & -2 & -1 & 0 & 1 & 2 & 3 & common \\
$\quad \ldots . .$. & -3 & -2 & -1 & 0 & 1 & 2 & 3 & $\ldots . .$. \\
Affinity & -3 & -2 & -1 & 0 & 1 & 2 & 3 & indifferent \\
advanced & -3 & -2 & -1 & 0 & 1 & 2 & 3 & low-level \\
\hline
\end{tabular}




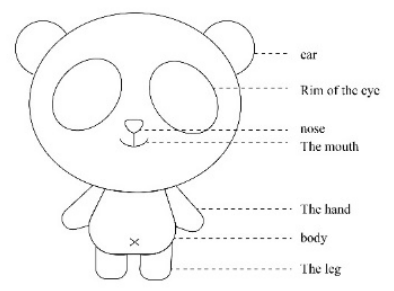

Figure 3. Mascot deconstruction

SPASS software was then used for principal component analysis, by entering a representative sample perceptual image average, and rectangular axis maximum variation method was performed according to the result of principal component analysis. Then we take three image factors whose values are greater than 1 , thus what participants feel about the mascot of cognition is composed of three image factors, in accordance with its attributes and meaning, images of the three factors can be classified as gender factors、 style factors as well as taste factors ${ }^{[1]}$. The positive factor load represents the positive evaluation, while the negative factor load represents the negative evaluation. After the factor analysis, the cumulative contribution value of the three factors is obtained. After the rotation matrix, the first type of factors are simple, round and advanced. The second kind of factor has the individuality, the creativity; Traditional and affinity, as shown in figure 4. Finally, the three factors advanced, creative and traditional are extracted for the later correlation analysis, and the cumulative contribution value of the three factors is obtained after factor analysis ${ }^{[3]}$.

Table 2. Kansei scoring matrix score table

\begin{tabular}{|c|c|c|c|c|c|c|c|c|}
\hline & personality & lovely & traditional & advanced & concise & creativity & amiable & fruity \\
\hline NO1 & -0.2353 & 0.0118 & -0.1529 & -0.0824 & 0.0235 & -0.1294 & -0.0471 & -0.1176 \\
\hline NO2 & -0.0706 & 0.1059 & -0.3529 & -0.0588 & -0.1647 & 0.1647 & -0.2118 & 0.0824 \\
\hline NO3 & -0.3882 & -0.1412 & -0.2471 & -0.2118 & -0.1176 & -0.1765 & -0.1059 & -0.1176 \\
\hline NO4 & -0.2706 & -0.0588 & -0.3529 & -0.3647 & -0.2588 & -0.1412 & -0.1882 & -0.2471 \\
\hline NO5 & 0.0471 & 0.0118 & -0.0941 & -0.3529 & -0.4000 & 0.0471 & -0.4118 & -0.5176 \\
\hline NO6 & -0.0353 & -0.0235 & -0.5059 & -0.1529 & -0.2941 & 0.0824 & -0.1765 & -0.1059 \\
\hline NO7 & -0.2706 & 0.0706 & -0.2824 & -0.2353 & -0.5412 & -0.1412 & -0.0353 & -0.1882 \\
\hline NO8 & -0.2353 & 0.0353 & -0.3412 & -0.6000 & -0.4824 & -0.1412 & -0.2118 & -0.1059 \\
\hline NO9 & -0.3412 & -0.3412 & -0.3412 & -0.3176 & -0.2588 & -0.1176 & -0.0706 & -0.1294 \\
\hline NO10 & 0.0235 & -0.2118 & -0.5176 & -0.4588 & -0.4706 & -0.1294 & -0.1529 & -0.4471 \\
\hline N011 & -0.0588 & 0.1647 & -0.2941 & -0.2471 & -0.3294 & 0.0588 & -0.0824 & -0.0353 \\
\hline N012 & -0.3412 & -0.1176 & -0.2941 & -0.5059 & -0.4588 & -0.2824 & -0.0353 & -0.1412 \\
\hline N013 & -0.2000 & 0.0353 & -0.3176 & -0.2235 & -0.4588 & -0.2588 & -0.4235 & -0.2118 \\
\hline NO14 & 0.0235 & -0.1176 & -0.2353 & -0.1882 & -0.2235 & -0.0824 & -0.0588 & -0.1412 \\
\hline NO15 & -0.1529 & -0.1647 & -0.4118 & -0.4118 & -0.4588 & -0.0706 & -0.1176 & -0.2588 \\
\hline N016 & -0.1412 & 0.0471 & -0.4235 & -0.2824 & -0.3647 & -0.2471 & -0.2000 & -0.1529 \\
\hline NO17 & -0.3647 & -0.2353 & -0.2941 & -0.2941 & -0.3294 & -0.0353 & -0.2471 & -0.2235 \\
\hline NO18 & -0.2706 & -0.0941 & -0.2588 & -0.3412 & -0.5412 & -0.2588 & -0.2235 & -0.2118 \\
\hline N019 & -0.4824 & 0.0235 & -0.3059 & -0.3529 & -0.3529 & -0.3882 & -0.2824 & -0.2471 \\
\hline NO20 & -0.3294 & -0.2118 & -0.2706 & -0.1647 & -0.2706 & 0.0353 & -0.2235 & -0.0941 \\
\hline NO21 & -0.4235 & -0.1176 & -0.3412 & -0.3176 & -0.3882 & -0.1882 & -0.1647 & -0.0471 \\
\hline average & -0.2151 & -0.0633 & -0.3160 & -0.2936 & -0.3401 & -0.1143 & -0.1748 & -0.1742 \\
\hline
\end{tabular}

In order to make the perceptual image more representative, clustering analysis was carried out on the eight adjectives and combined it with data from factor calculation, as shown in figure 5. The distance of each image context from its group of center is calculated by coordinates of each image, and the shortest one among 
them is the representative of the group of image semantics, lastly, the next pairs of image semantics used in the next stage of experiment namely advanced, individuality, traditional was selected ${ }^{[4]}$.

\section{3. construct modeling semantic space}

Using morphological analysis to influence people perceptual image judgment modelling factor decomposition, looking for the individual factors of the decomposed variable element, as shown in figure 4, which will be the mascot of the shape of the deconstructed ten projects, 34 categories, including deconstruction projects form have head, mouth, eyes, nose, limbs and trunk, position can be divided into the extremities accounted for the proportion of the body, the rim of the eye of facial proportions, the transition of the neck, overall relationship has a head body scale, etc. The morphological elements of the mascot are respectively represented by $a-h$, and the characteristics of each morphological element are respectively represented by serial Numbers ${ }^{[5]}$, as shown in table 3 .

\begin{tabular}{|c|c|c|r|}
\hline & \multicolumn{3}{|c|}{ component } \\
\cline { 2 - 4 } & 1 & 2 & 3 \\
\hline concise & 0.823 & & \\
fruity & & & \\
high-level & 0.776 & & \\
personality & 0.760 & & \\
creativity & & 0.909 & \\
traditional & & 0.782 & 0.791 \\
amiable & & & -0.592 \\
lovely & & & \\
\hline
\end{tabular}

Figure 4. Component matrix after factor rotation

Table 3. Morphological deconstruction feature table

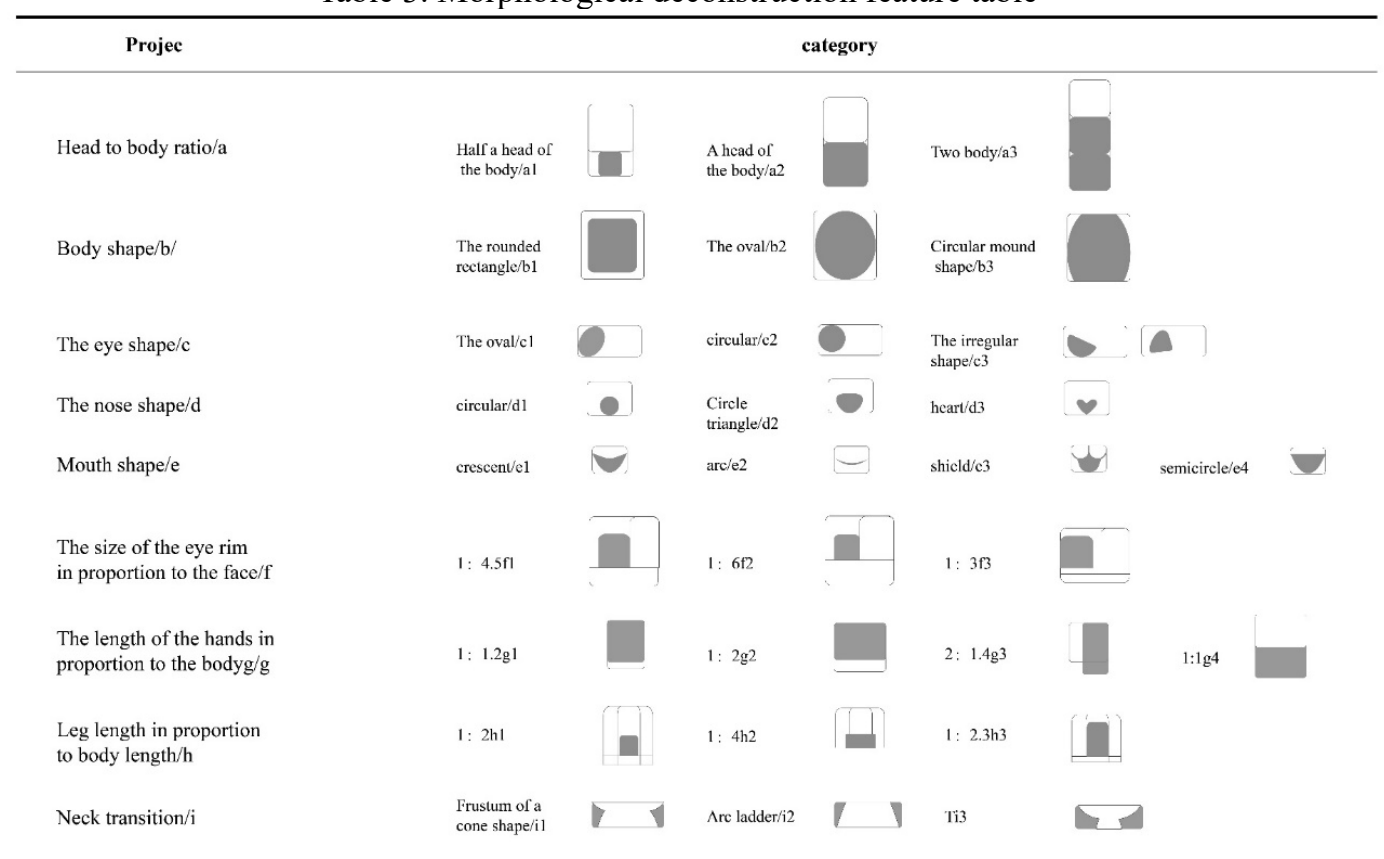

\section{Research on the relationship between image vocabulary and morphological elements}

\section{1. establish a correlation model between perceptual images and mascot modeling elements}

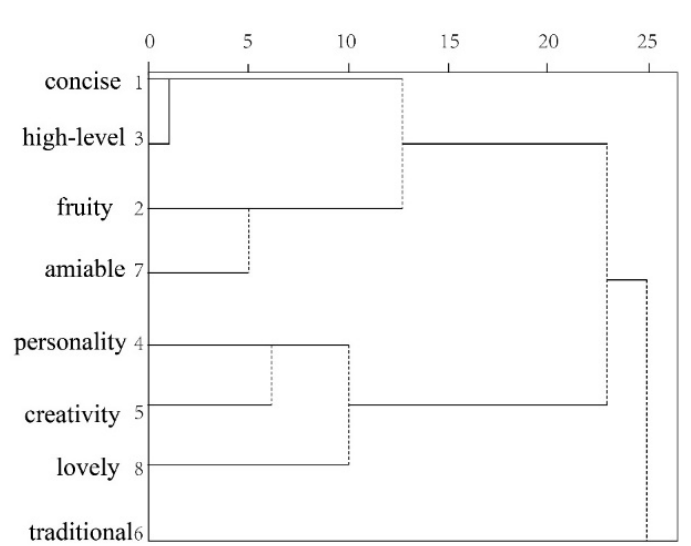

Figure 5. Cluster analysis tree of eight perceptual terms 
samples, The matrix thinking can be used to quantitatively transform it into an editable data format. The specific method is: through the analysis of the characteristics of the modeling elements of the mascot, the independent variable corresponding to the characteristics of the corresponding elements is assigned to 1 . Other attributes that do not match are assigned to $0^{[6]}$. Finally, after analysis, we can only get the matrix containing " 0 " and " 1 ", as shown in Table 4.

Table 4. Modeling reaction matrix

\begin{tabular}{|c|c|c|c|c|c|c|c|c|c|c|c|c|c|c|c|c|c|c|c|c|c|c|c|c|c|c|c|c|c|}
\hline & a1 & $\mathrm{a} 2$ & a3 & b1 & b2 & b3 & c1 & c2 & c3 & d1 & d2 & d3 & el & c2 & e3 & e4 & fi & 12 & $\mathrm{f3}$ & g1 & $\mathrm{g} 2$ & $\mathrm{~g} 3$ & g4 & h1 & h2 & h3 & i1 & i2 & i3 \\
\hline Picture 1 & 0 & 1 & 0 & 1 & 0 & 0 & 1 & 0 & 0 & 0 & 1 & 0 & 0 & 0 & 1 & . & 1 & 0 & 0 & 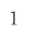 & 0 & 0 & 0 & 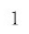 & 0 & 0 & & & 1 \\
\hline Picture 2 & 0 & 1 & 0 & 0 & 1 & 0 & 0 & 1 & 0 & 1 & 0 & 0 & 0 & 1 & 0 & . & 0 & 1 & 0 & 2 & 0 & 0 & . & 0 & 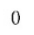 & $x^{2}$ & & & 0 \\
\hline Picture 3 & 0 & 1 & 0 & 1 & 0 & 0 & 1 & 0 & 0 & 0 & 0 & 1 & 0 & 0 & 1 & 0 & 0 & 0 & 1 & . & 1 & 0 & 0 & 0 & 1 & 0 & & & 0 \\
\hline Picture 4 & 0 & 1 & 0 & 0 & 1 & 0 & 1 & 0 & 0 & 0 & 1 & 0 & 1 & 0 & 0 & 0 & 1 & 0 & 0 & 0 & 0 & 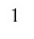 & 0 & 0 & 0 & 3 & & & 1 \\
\hline Picture 5 & 1 & 0 & 0 & 1 & 0 & 0 & 0 & 0 & 1 & 0 & 0 & 1 & 0 & 0 & 0 & 1 & 1 & 0 & 0 & 0 & 1 & 0 & 0 & 1 & 0 & 0 & & & 0 \\
\hline Picture 6 & 0 & 1 & 0 & 0 & 1 & 0 & 1 & 0 & 0 & 0 & 1 & 0 & 0 & 1 & 0 & 0 & 0 & 0 & 1 & 0 & 0 & 0 & 1 & 1 & 0 & 0 & 1 & & 0 \\
\hline Picture 7 & 0 & 1 & 0 & 0 & 0 & 1 & 1 & 0 & 1 & 0 & 0 & 1 & 0 & 1 & 0 & 0 & 1 & 0 & 0 & 年 & 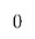 & 1 & 0 & 0 & 0 & . & & & 0 \\
\hline Picture 8 & 0 & 0 & 1 & 0 & 1 & 0 & 0 & 1 & 0 & 1 & 0 & 0 & 0 & 1 & 0 & 0 & 0 & 0 & 1 & 0 & 0 & 0 & 1 & 1 & 0 & 0 & & & 0 \\
\hline Picture 9 & 0 & 0 & 1 & 0 & 0 & 1 & 0 & 1 & 0 & 0 & 1 & 0 & 0 & 0 & 0 & 1 & 0 & 1 & 0 & 0 & 1 & 0 & 0 & 1 & 0 & 0 & & & 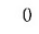 \\
\hline Picture 10 & 10 & 0 & 1 & 0 & 1 & 0 & 1 & 0 & 0 & 0 & 1 & 0 & 0 & 1 & 0 & 0 & 0 & 1 & 0 & . & 0 & , & 0 & 0 & 1 & 0 & 0 & 1 & 0 \\
\hline Picture 11 & 0 & 0 & 1 & 0 & 1 & 0 & 1 & 0 & 0 & 0 & 0 & 1 & 0 & 1 & 0 & 0 & 0 & 0 & 1 & 0 & 0 & 1 & 0 & 1 & 0 & 0 & & & 0 \\
\hline
\end{tabular}

\begin{tabular}{|c|c|c|c|c|c|c|c|c|c|c|c|c|c|c|c|c|c|c|c|c|c|c|c|c|c|c|c|c|c|}
\hline & a1 & $\mathrm{a} 2$ & a3 & b1 & b2 & b3 & c1 & c2 & c3 & d1 & d2 & d3 & e1 & e2 & e3 & e4 & f1 & I2 & 13 & g1 & g2 & $\mathrm{g} 3$ & $\mathrm{~g} 4$ & h1 & h2 & h3 & i1 & $\mathrm{i} 2$ & i3 \\
\hline Picture 12 & 0 & 1 & 0 & 0 & 1 & 0 & 1 & 0 & 0 & 0 & 0 & 1 & 0 & 1 & 0 & 0 & 0 & 0 & 1 & 0 & 1 & 0 & 1 & 0 & 1 & 0 & 0 & 1 & 0 \\
\hline Pieture 1 & 1 & 0 & 0 & 1 & 0 & 0 & 0 & 1 & 0 & 0 & 0 & 1 & 0 & 1 & 0 & 0 & 1 & 0 & 0 & 0 & 0 & 0 & 1 & 0 & 1 & 0 & 1 & 0 & 0 \\
\hline Picture 14 & 0 & 1 & 0 & 1 & 0 & 0 & 0 & 1 & 0 & 0 & 0 & 1 & 0 & 0 & 1 & 0 & 0 & 0 & 1 & 0 & 0 & 0 & 1 & 0 & 1 & 0 & 1 & 0 & 0 \\
\hline Picture 15 & 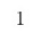 & 0 & 0 & 0 & 0 & 1 & 1 & 0 & 0 & 0 & 0 & 1 & 0 & 1 & 0 & 0 & 1 & 0 & 0 & 0 & 0 & 0 & 1 & 0 & 0 & 1 & 0 & 0 & 1 \\
\hline Picture 16 & 1 & 0 & 0 & 1 & 0 & 0 & 1 & 0 & 0 & 0 & 1 & 0 & 0 & 1 & 0 & 1 & 0 & 1 & 0 & 0 & 0 & 0 & 1 & 0 & 0 & 1 & 0 & 0 & 1 \\
\hline Picture 17 & 0 & 1 & 0 & 0 & 0 & 1 & 1 & 0 & 0 & 1 & 0 & 0 & 0 & 1 & 0 & 0 & 1 & 0 & 0 & 0 & 1 & 0 & 0 & 0 & 1 & 0 & 0 & 0 & 1 \\
\hline Picture 18 & 0 & 1 & 0 & 0 & 1 & 0 & 1 & 0 & 1 & 0 & 0 & 1 & 0 & 0 & 1 & 0 & 0 & 0 & 1 & 0 & 0 & 0 & 1 & 0 & 0 & 1 & 0 & 0 & 1 \\
\hline Picture 19 & 0 & 1 & 0 & 1 & 0 & 0 & 1 & 0 & 0 & 1 & 0 & 0 & 0 & 0 & 1 & 0 & 0 & 0 & 1 & 0 & 0 & 0 & 1 & 0 & 0 & 1 & 0 & 0 & 1 \\
\hline Picture 20 & 0 & 1 & 0 & 1 & 0 & 0 & 1 & 0 & 0 & 1 & 0 & 0 & 0 & 0 & 0 & 1 & 1 & 0 & 0 & 0 & 0 & 0 & 1 & 0 & 0 & 1 & 0 & 0 & 1 \\
\hline Picture 21 & 0 & 1 & 0 & 0 & 0 & 1 & 0 & 1 & 0 & 1 & 0 & 0 & 0 & 0 & 0 & 1 & 0 & 0 & 1 & 0 & 1 & U & 0 & 0 & 1 & 0 & 0 & 0 & 1 \\
\hline
\end{tabular}

Taking the average value of perceptual semantic evaluation as dependent variable and the response value of modeling elements as independent variable, the following multivariate linear mathematical prediction model is established.

$y=\mathrm{y}=\mathrm{g}_{\mathrm{a} 1} \mathrm{a}_{1}+\mathrm{g}_{\mathrm{a} 2} \mathrm{a}_{2}+\mathrm{g}_{\mathrm{a} 3} \mathrm{a}_{3}+\mathrm{g}_{\mathrm{b} 1} \mathrm{~b}_{1}+\mathrm{g}_{\mathrm{b} 2} \mathrm{~b}_{2}+\mathrm{g}_{\mathrm{b} 3} \mathrm{~b}_{3}+\mathrm{g}_{\mathrm{c} 1} \mathrm{c}_{1}$ $+\mathrm{g}_{\mathrm{c} 2} \mathrm{c}_{2}+\mathrm{g}_{\mathrm{c} 3} \mathrm{c}_{3}+\mathrm{g}_{\mathrm{d} 1} \mathrm{~d}_{1}+\mathrm{g}_{\mathrm{d} 2} \mathrm{~d}_{2}+\mathrm{g}_{\mathrm{d} 3} \mathrm{~d}_{3}+\mathrm{g}_{\mathrm{e} 1} \mathrm{e}_{1}+\mathrm{g}_{\mathrm{e} 2} \mathrm{e}_{2}+\mathrm{g}_{\mathrm{e} 3} \mathrm{e}_{3}$ $+\mathrm{g}_{\mathrm{e} 4} \mathrm{e}_{4}+\mathrm{g}_{\mathrm{f} 1} \mathrm{f}_{1}+\mathrm{g}_{\mathrm{f} 2} \mathrm{f}_{2}+\mathrm{g}_{\mathrm{f} 3} \mathrm{f}_{3}+\mathrm{g}_{\mathrm{g} 1} \mathrm{~g}_{1}+\mathrm{g}_{\mathrm{g} 2} \mathrm{~g}_{2}+\mathrm{g}_{\mathrm{g} 3} \mathrm{~g}_{3}+\mathrm{g}_{\mathrm{g} 4} \mathrm{~g}_{4}+\mathrm{g}_{\mathrm{h} 1} \mathrm{~h}_{1}$ $+\mathrm{g}_{\mathrm{h} 2} \mathrm{~h}_{2}+\mathrm{g}_{\mathrm{h} 3} \mathrm{~h}_{3}+\mathrm{g}_{\mathrm{i} 1} \mathrm{i}_{1}+\mathrm{g}_{\mathrm{i} 2} \mathrm{i}_{2}+\mathrm{g}_{\mathrm{i} 3} \mathrm{i}_{3}+\mathrm{m}$

$\mathrm{y} \longrightarrow$ Average value of perceptual semantic evaluation;

$\mathrm{g}_{\mathrm{ij}}$ Weight coefficient of each independent variable; $\mathrm{a}_{\mathrm{i} \sim} \mathrm{i}_{\mathrm{i}}-$ Modeling element response value;

$\mathrm{m}-$ Constant term.

Through statistical software SPASS linear regression analysis, which needs the input of the dependent variable is $\mathrm{q}$ is obtained by a questionnaire test on average, the evaluation of the emotional vocabulary and need to participate in the linear regression analysis is mascot representative sample modelling characteristic element matrix quantitative values, thick model parameters related data, including the partial correlation coefficient, category score, multiple correlation coefficient, constant value, such as in table 5 .

Table 5. Results of the semantic "individual-common" analysis

Design Design Category Coefficient of project category scores partial correlation

\begin{tabular}{|c|c|c|c|}
\hline \multirow{2}{*}{$\mathrm{a}$} & $\mathrm{a}_{1}$ & 0.041 & \multirow{2}{*}{0} \\
\cline { 2 - 3 } & $\mathrm{a}_{2}$ & -0.112 & \multirow{2}{*}{0.624} \\
\cline { 2 - 3 } & $\mathrm{a}_{3}$ & 0.197 & \\
\hline \multirow{2}{*}{$\mathrm{b}$} & $\mathrm{b}_{1}$ & 0.835 & \multirow{2}{*}{} \\
\cline { 2 - 3 } & $\mathrm{b}_{2}$ & 0.547 & 0.236 \\
\hline
\end{tabular}

Design Design Category Coefficient of project category scores partial correlation

\begin{tabular}{|c|c|c|c|}
\hline \multirow{4}{*}{$\mathrm{f}$} & $\mathrm{f}_{1}$ & 0.463 & \multirow{2}{*}{0.479} \\
\cline { 2 - 3 } & $\mathrm{f}_{2}$ & 0.244 & \multirow{2}{*}{0.49} \\
\cline { 2 - 3 } & $\mathrm{f}_{3}$ & 0.380 & \\
\hline \multirow{3}{*}{$\mathrm{g}$} & $\mathrm{g}_{1}$ & -.0484 & \multirow{2}{*}{} \\
\cline { 2 - 3 } & $\mathrm{g}_{2}$ & -0.345 & 0.036 \\
\hline
\end{tabular}




\begin{tabular}{|c|c|c|c|}
\hline & $b_{3}$ & 0.306 & \\
\hline \multirow{3}{*}{$\mathrm{c}$} & $\mathrm{c}_{1}$ & 0.406 & \multirow{3}{*}{0.118} \\
\hline & $\mathrm{c}_{2}$ & -0.173 & \\
\hline & $\mathrm{c}_{3}$ & 0.634 & \\
\hline \multirow{3}{*}{ d } & $\mathrm{d}_{1}$ & -0.255 & \multirow{3}{*}{0.052} \\
\hline & $d_{2}$ & -0.117 & \\
\hline & $\mathrm{d}_{3}$ & 0.671 & \\
\hline \multirow{4}{*}{$\mathrm{e}$} & $e_{1}$ & 0.213 & \multirow{4}{*}{0.108} \\
\hline & $\mathrm{e}_{2}$ & 0.503 & \\
\hline & $e_{3}$ & 0.200 & \\
\hline & $\mathrm{e}_{4}$ & 0.082 & \\
\hline
\end{tabular}

Therefore, according to the analysis results shown in Table 5, we can see that the "individual-ordinary" perceptual image is related to the modeling elements of the mascot.

The associated multivariate linear prediction model is: $\mathrm{Y}=0.041 \mathrm{a}_{1}-0.112 \mathrm{a}_{2}+0.197 \mathrm{a}_{3}+0.835 \mathrm{~b}_{1}+0.547 \mathrm{~b}_{2}+0.306 \mathrm{~b}_{3}$ $+0.406 c_{1}-0.173 c_{2}+0.634 c_{3}-0.255 d_{1}-0.117 d_{2}+0.671 d_{3}$

\begin{tabular}{|c|c|l|c|}
\hline \multirow{2}{*}{} & $\mathrm{g}_{3}$ & 0.140 & \\
\cline { 2 - 3 } & $\mathrm{g}_{4}$ & -0.276 & \\
\hline \multirow{3}{*}{$\mathrm{h}$} & $\mathrm{h}_{1}$ & 0.217 & \multirow{2}{*}{0.368} \\
\cline { 2 - 3 } & $\mathrm{h}_{2}$ & -0.121 & \\
\cline { 2 - 3 } & $\mathrm{h}_{3}$ & 0.112 & \multirow{2}{*}{0.481} \\
\hline \multirow{3}{*}{$\mathrm{g}$} & $\mathrm{i}_{1}$ & -0.003 & \\
\cline { 2 - 3 } & $\mathrm{i}_{2}$ & 0.521 & \\
\cline { 2 - 3 } & $\mathrm{i}_{3}$ & 0.371 & \\
\hline \multicolumn{3}{|c|}{ Constant term:0.345 } \\
\hline \multicolumn{3}{|c|}{ Multiple correlation coefficient:0.736 } \\
\hline \multicolumn{3}{|c|}{ Coefficient of determination:0.825 } \\
\hline
\end{tabular}

$+0.213 \mathrm{e}_{1}+0.503 \mathrm{e}_{2}+0.2 \mathrm{e}_{3}+0.082 \mathrm{e}_{4}+0.463 \mathrm{f}_{1}+0.244 \mathrm{f}_{2}$ $+0.380 \mathrm{f}_{3}-0.484 \mathrm{~g}_{1}-0.345 \mathrm{~g}_{2}+0.14 \mathrm{~g}_{3}-0.276 \mathrm{~g}_{4}+0.217 \mathrm{~h}_{1}-$ $0.121 \mathrm{~h}_{2}+0.112 \mathrm{~h}_{3}-0.003 \mathrm{i}_{1}+0.521 \mathrm{i}_{2}+0.371 \mathrm{i}_{3}+0.345$

\section{2 conclusion analysis}

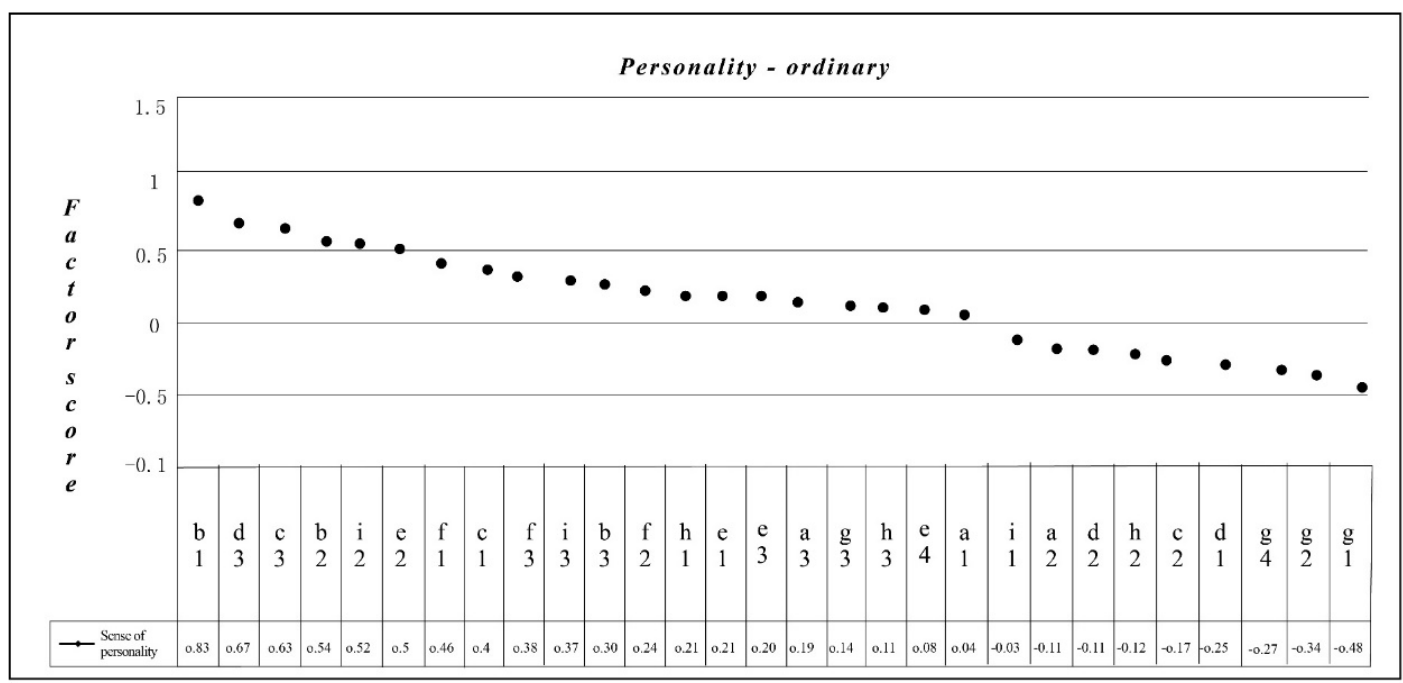

Figure 6. Score of each modeling element

Complex correlation coefficient is an index that reflects the degree of correlation between independent variables and dependent variables of a model. the larger the coefficient data is, the higher the linear correlation degree between elements and variables is. In order to verify the accuracy of the model, the square of the complex correlation coefficient is usually used to judge the determination coefficient. In a prediction equation, the closer $\mathrm{R}$ is to 1 , the higher the accuracy of the prediction model. Generally speaking, the determination coefficient above 0.8 means that the fitting accuracy of the equation is better ${ }^{[7]}$. It can be seen from figure 6 that the $\mathrm{R}$ values representing the relationship between the morphological elements and perceptual images of the sample are all greater than 0.7 , indicating that there is a very strong relationship between the observed value and the predicted knowledge ${ }^{[8]}$ 。

The magnitude of the partial correlation coefficient reflects the influence of each project on the perceptual image of the mascot. As for the perceptual image phrase "individual-ordinary" in Table 5, it is analyzed from small to large according to the partial correlation coefficient shown in the table. it is concluded that the influence degree of each item is as follows: the ratio of head to body \&gt; the transition of neck \&gt; the ratio of eye circle to face \&gt; the ratio of leg length to body \&gt; the shape of 
mouth \&gt; the shape of nose \&gt; the ratio of hand length to body. By obtaining the degree of influence of the mascot element attributes on the emotional image, it can be used as a reference for the design process, that is, when the relevant emotional feelings need to be expressed, priority should be given to the influential mascot attributes.

The category score indicates the influence degree and emphasis direction of different categories on perceptual images in each project, the positive value indicates the positive meaning, and the negative value means the opposite meaning. Taking personality as an example, as shown in figure 6 , we can see that the mascot modeling elements category in the case of "rounded rectangular body $b_{1}$ " has the highest contribution to it, followed by "heart-shaped nose $\mathrm{d}_{3}$ "; in addition, the shape of the torso is "oval $\mathrm{b}_{2}$ ", the neck transition "arc trapezoid $\mathrm{i}_{2}$ ", the mouth shape is "arc $\mathrm{e}_{2}$ ", "and so on also positively affect the" personality "image of the mascot. The negative part of the category shows that "nose shape" and "the proportion of hand length to body" have a high degree of influence on the "ordinary" image of the mascot, and the "common sense" is the strongest in "round triangle $\mathrm{D}_{2}$ " and "1:2g $\mathrm{g}_{2}$

Therefore, in the design of mascots that need to reflect high-level feelings, because it is most closely related to ", the first thing that needs to be considered is that the topic is based on harmony, and it is the second item that needs to be paid attention to.

\section{Conclusion}

On the basis of Kansei engineering, this paper makes a quantitative study on the emotional tendency of the mascot to the audience. The semantic difference method is used to obtain the audience's perceptual image evaluation of the mascot shape, and the factor analysis is used to extract the main factors. At the same time, the morphological analysis method is used to deconstruct the basic structural attributes of the font and divide the features. The quantitative I theory establishes a mathematical model between mascot modeling features and emotional tendency, which makes it possible to predict the emotional tendency of mascot expression according to the objective factors of mascot design. Thus, to a certain extent, it can provide guidance for the design of the mascot, that is, on the basis of determining what kind of emotion the designer needs to express, the designer should follow the characteristics of the mascot structure which has obvious influence on this emotion.

\section{Reference}

1. Fu CJ, Bi YG, Shen XH. (2020) Based on the perceptual technology frame glasses modelling image study [J]. Journal of packaging engineering.

2. Yao X, Hu HY, Li JX. (2014)Body profile modelling design research based on perceptual engineering $[\mathrm{J}]$. Journal of packaging engineering.

3. Chen GQ, Jiang N, Zhang P, Liu YH. Children with robot based on perceptual engineering design study
[J].

4. Zhang S, (2019)Based on perceptual engineering font emotional images [J]. Journal of research and application of Beijing university of posts and telecommunications, 2019.

5. Yuan Y, Liu WJ . (2016)Office chair perceptual image and form elements association studies [J]. Journal of forestry engineering.

6. YU N, Zhang C, Du Y,(2018) wang H. Based on the theory of quantification, furniture modelling image design [J]. Journal of packaging engineering.

7. Hong BY. (2018)Traditional recommended form of visual imagery research $[\mathrm{J}]$. Journal of graphics.

8. Li MZ, He CY, LU ZP, Yang S. (2016)Based on the theory of quantification I class car image modelling design research $[\mathrm{J}]$. Journal of mechanical design. 